Chronic Obstructive Pulmonary Diseases:

Journal of the COPD Foundation

COPD

rovuntiflon

\author{
Original Research
}

\title{
A Novel Approach to Screening for Alpha-1 Antitrypsin Deficiency: Inpatient Testing at a Teaching Institution
}

James J. Tasch, DO ${ }^{1}$ Ann T. McLaughlan, DO ${ }^{1}$ Asad A. Nasir, MD ${ }^{1}$

\begin{abstract}
Chronic obstructive pulmonary disease (COPD) currently affects more than 16 million Americans and it is estimated that roughly 100,000 Americans have undiagnosed, severe alpha-1 antitrypsin deficiency (AATD) (Chest. 2005;128[3]:1179-1186) (Chest. 2002;122[5]:1818-1829). Patients with AATD have an accelerated rate of decline of lung function caused by proteolytic enzymes. The morbidity associated with this inherited disorder is preventable due to the availability of augmentation therapy. Appropriate inpatient screening of patients with COPD for AATD is lacking and most screening is exclusively limited to outpatient pulmonary clinics. Between May 2016 and February 2017, genetic screening was completed on 54 individuals who were admitted with either a former diagnosis of COPD or active COPD exacerbation to Arnot Ogden Medical Center (AOMC) in Elmira, New York. The incorporation of inpatient genetic screening by resident physicians for AATD in COPD patients led to a high rate of screened and newly diagnosed AATD carriers with a variety of AATD genotypes. It is recommended that there should be an expansion of screening for AATD in hospitalized patients with COPD, regardless of age or smoking history.
\end{abstract}

Abbreviations: chronic obstructive pulmonary disease, COPD; alpha-1 antitrypsin deficiency, AATD; Arnot Ogden Medical Center, AOMC; American Thoracic Society, ATS; European Respiratory Society, ERS; electronic medical record, EMR; Global initiative for chronic Obstructive Lung Disease, GOLD

Funding Support: Grifols provided free testing supplies, materials and funding for the blood analyses.

Date of Acceptance: November 8, 2017

Citation: Tasch JJ, McLaughlan AT, Nasir AA. A novel approach to screening for alpha-1 antitrypsin deficiency: inpatient testing at a teaching institution. Chronic Obstr Pulm Dis. 2018;5(2):106-110. doi: https://doi.org/10.15326/jcopdf.5.2.2017.0170

\section{This article contains an online supplement.}

1 Graduate Medical Education, Arnot Ogden Medical Center, Elmira, New York

\section{Address correspondence to:}

James Tasch, DO

600 Roe Ave

Elmira, New York 14905

Phone: 607-737-4100

Email: james.tasch@steward.org

\section{Keywords:}

alpha-1 antitrypsin deficiency; AAT; chronic obstructive pulmonary disease; COPD; genetic screening; resident physician; inpatient; AAT carriers

\section{Introduction}

Alpha-1 antitrypsin deficiency (AATD) is a genetic disorder known to be associated with early onset chronic obstructive pulmonary disease (COPD) and liver disease. ${ }^{1,2}$ AATD is relatively common in populations of European ancestry, with an estimated prevalence of 1 case per 3000 to 5000 persons in the United States. ${ }^{3}$ AATD can be difficult to diagnose as many patients commonly present with generic respiratory complaints often mistaken for other respiratory syndromes such as asthma or smoking-related COPD. ${ }^{4}$ The delay between the onset of symptoms and time of diagnosis of AATD patients exceeds 5 years. ${ }^{5}$ The 2003 clinical guidelines of the American Thoracic Society (ATS) and the European Respiratory Society (ERS) recommend 
AATD testing for all patients with COPD, emphysema, or asthma with irreversible airflow obstruction. ${ }^{3,6}$ Updated guidelines created by the Alpha-1 Foundation and published in the Journal of the COPD Foundation in 2016, again reinforce the recommendation to test all individuals with COPD regardless of age or ethnicity. ${ }^{1}$ Despite having clear recommendations for AATD screening, testing remains low and is almost exclusively limited to outpatient pulmonary clinics.

Since early diagnosis of the disease could prompt initiation of therapy, screening programs have been developed as a strategy to increase detection (of AATD) in the United States. ${ }^{2,7}$ Poor awareness by health care professionals is a large reason for the lack of routine screening for AATD. An example that helps facilitate awareness is the distribution of free AATD test kits. Another more recent strategy involved further educating respiratory therapists about AATD which led to an increased referral for screening. ${ }^{8}$ Yet another strategy to increase focused screening is to utilize pulmonary function laboratory personnel to test patients found to have fixed airflow obstruction while undergoing pulmonary function tests. ${ }^{9}$ A common misconception by providers is that individuals newly diagnosed with COPD who have a significant smoking history do not need to be screened for AATD. This study was designed to test the feasibility of inpatient screening for AATD utilizing resident physicians as a medium to help collect samples while simultaneously spreading awareness of this genetic disorder.

\section{Methods}

This feasibility study was approved by the institutional review board of Arnot Ogden Medical Center (AOMC) in Elmira, New York. The inclusion criteria were selected to be in conjunction with the 2003 guidelines put forth by the ATS and the ERS as well as the 2016 Alpha-1 Foundation guidelines. ${ }^{1,6}$ Individuals were required to be 18-years-old or older and admitted to $A O M C$ with either an active COPD exacerbation or a previous diagnosis of COPD via pulmonary function testing. All physicians who admitted patients at AOMC were informed of this study via multiple modalities and were encouraged to enroll their patients. Modalities included reminder mass notifications utilizing both electronic medical record (EMR)-based messaging and health network-based emails, printed reminders which were placed at all commonly used computers, and routine verbal reminders at resident conferences. A custom nursing notification order was added into the hospital's electronic health care software allowing for physician-friendly, time-efficient referral to the study. Through a texting service compliant with the Health Insurance Portability and Accountability Act, nursing staff notified a group of resident physicians of each new referral.

A resident physician associated with the "Alpha-1 Team" obtained informed consent utilizing a premade consent form allowing for the participation in the study and collection of a small blood sample. A brief questionnaire (online supplement), which incorporated previous pulmonary function testing results, smoking history, medical and family history, and contact information, was completed by the resident physician and the patient. An AATD brochure was given to the individual being screened in compliance with New York State policy. Utilizing free AATD testing kits, provided by Grifols pharmaceuticals, a blood sample was collected and sent to GeneAidyx LLC Alpha-1 Antitrypsin Genetics Laboratory for further analysis. Results were reported and reviewed within 2-3 weeks of screening. Any positive findings prompted a referral of the individual for an outpatient visit with a pulmonologist.

\section{Results}

Demographics of the study population are listed in Table 1 . There was a male to female ratio of nearly $1: 1$ with most participants older than 45 years old. A total of $71 \%$ of the individuals screened carried a diagnosis of Global initiative for chronic Obstructive Lung Disease stage 3 or 4 COPD. ${ }^{10}$ As expected, tobacco use was predominant in our patient population, with $47 \%$ being active smokers. Perhaps most importantly, only $54 \%$ of individuals evaluated were being currently followed by a pulmonologist with more than $75 \%$ of them having been hospitalized for a COPD-related issue prior to the admission in which they were screened for AATD. To date, this study has led to the discovery of 12 individuals (22.2\% of the screened patients) with a variant genotype of AATD (Figure 1). There were 5 individuals with $\mathrm{PI}^{*} \mathrm{MS}$ genotype, 6 patients with $\mathrm{PI}^{*} \mathrm{MZ}$ genotype, and 1 individual with $\mathrm{PI}^{*} \mathrm{SZ}$ genotype with associated range of alpha-1 antitrypsin levels of 84.3 to $192.6 \mathrm{mg} /$ dL, 74.6 to $208.4 \mathrm{mg} / \mathrm{dL}$, and $70.6 \mathrm{mg} / \mathrm{dL}$ respectively. Additionally, 1 individual who was a newly diagnosed AATD carrier from this study, referred their child 


\section{Table 1. Cumulative Characteristics of All Persons Screened}

Age (years)

\begin{tabular}{|c|c|}
\hline $18-45$ & $1(2 \%)$ \\
\hline $46-65$ & $23(43 \%)$ \\
\hline $66-88$ & 30 (55\%) \\
\hline \multicolumn{2}{|l|}{ Gender } \\
\hline Male & $28(52 \%)$ \\
\hline Female & $26(48 \%)$ \\
\hline \multicolumn{2}{|l|}{ COPD (GOLD stage) } \\
\hline unknown & $5(9 \%)$ \\
\hline stage 1 & $2(4 \%)$ \\
\hline stage 2 & $9(17 \%)$ \\
\hline stage 3 & 22 (41\%) \\
\hline stage 4 & $16(30 \%)$ \\
\hline \multicolumn{2}{|c|}{ Hospitalized Previously for COPD } \\
\hline Yes & $41(76 \%)$ \\
\hline No & $13(24 \%)$ \\
\hline
\end{tabular}

\section{Smoking History (pack years)}

\begin{tabular}{r|r}
\hline Non-smoker & $2(4 \%)$ \\
\hline $1-19$ & $3(5 \%)$ \\
\hline $20-40$ & $25(46 \%)$ \\
\hline $41-60$ & $15(28 \%)$ \\
\hline COPD Diagnosed Before age 45 & $9(17 \%)$ \\
\hline Yes & $12(22 \%)$ \\
\hline No & $42(78 \%)$ \\
\hline
\end{tabular}

\section{Family History of COPD}

\begin{tabular}{c|c}
\hline Yes & $20(37 \%)$ \\
\hline No & $34(63 \%)$ \\
\hline
\end{tabular}

\section{Home Oxygen $^{\text {a }}$}

\begin{tabular}{r|r}
\hline No & $22(41 \%)$ \\
\hline Nocturnal Only & $7(13 \%)$ \\
\hline Continuous Use & $25(46 \%)$ \\
\hline
\end{tabular}

Followed by a Pulmonologist

\begin{tabular}{|c|c|}
\hline Yes & $29(54 \%)$ \\
\hline No & $25(46 \%)$ \\
\hline
\end{tabular}

Previous Exposure to Glass, Sandblasting, or Asbestos

\begin{tabular}{c|c} 
Yes & $11(20 \%)$ \\
\hline No & $43(80 \%)$ \\
\hline
\end{tabular}

aArnot Ogden Medical Center in Elmira, New York is at an approximate altitude of 942 feet (287 meters).

$\mathrm{COPD}=$ chronic obstructive pulmonary disease; $\mathrm{GOLD}=\mathrm{Global}$ initiative for chronic Obstructive Lung Disease

\section{Figure 1. Total Number of Individuals Diagnosed by Genotype}

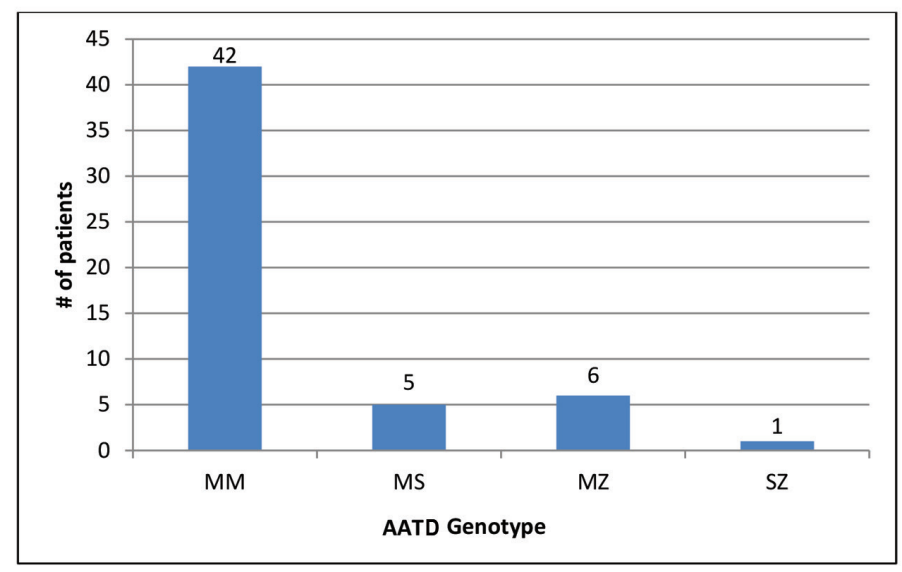

MM is the wildtype genotype.

AATD $=$ alpha- 1 antitrypsin deficiency

for screening who was subsequently found to have a $\mathrm{PI}^{*} \mathrm{MZ}$ genotype.

\section{Discussion}

AATD is one of the most common autosomal genetic disorders in humans, although it is still considered a rare recessive hereditary disorder and is significantly underdiagnosed. $^{11}$ For many individuals, a true diagnosis may take years, even after symptoms appear, leading to significant disease progression and irreversible lung damage. ${ }^{1}$ According to the ATS/ ERS recommendations, all patients with COPD and asthma (not fully reversible after bronchodilator therapy) should be tested for AATD. ${ }^{12}$ Largely, these recommendations are not being followed. Potential reasons for that include lack of awareness about the disease and the appropriate tests. ${ }^{5}$ The utilization of resident physicians to screen patients was done in part to help promote, among young physicians, the awareness of prevalence and treatment options of AATD.

There have been attempts to improve timing of diagnosis by implementing mass screening techniques in the general population and in newborns, but these are obviously limited by the high costs that can prohibit any large-scale screening program. The vast majority of modern day screening for AATD takes place in outpatient pulmonary offices. This study addressed the void of inpatient screening and targeted 
individuals admitted with a formal diagnosis of COPD via pulmonary function testing or had an active COPD exacerbation. There was no exclusion for comorbidities, age, medical compliance or tobacco exposure.

There were challenges throughout the implementation of this novel screening method. The first was the need for frequent reminders to all providers to refer their patients to the study due to the presumed "not important" status for screening for AATD. Another challenge was overcoming the physician assumptions that age and/or smoking history disqualified their patients for screening. Overall, through continued reinforcement of appropriate screening criteria, physicians began referring more patients. This study would have been strengthened if the patients who qualified, but were not referred by providers for screening, had been tracked. Strategies for implementing EMR-based automatic reminders to providers are being investigated for further improvements in both referral rates as well as eliminating the possibility of referring an already screened individual.

There are numerous benefits of screening for AATD. The most obvious benefit is to potentially qualify a patient for augmentation therapy with alpha-1 antitrypsin protein from donor plasma. Other benefits include: more effective smoking cessation counseling, ability to qualify family members for screening prior to developing significant disease, and the ability to provide individuals with more focused genetic counseling. More effective health care management and modification of lifestyle, such as smoking cessation, can be undertaken in individuals with AATD to help prevent the development of lung disease. ${ }^{13}$

There was an extraordinarily high percentage of individuals newly diagnosed as AATD carriers in this study as compared to the general population. This may be a selection bias based on the inpatient cohort selection. According to GeneReviews, ${ }^{14}$ North America AATD carriers are estimated to be $4.8 \%$ $\mathrm{PI}^{*} \mathrm{MS}, 2.1 \% \mathrm{PI}^{*} \mathrm{MZ}$, 0.1\% PI*SZ. This feasibility study of 54 individuals resulted in $9.2 \% \mathrm{PI}^{*} \mathrm{MS}, 11.1 \%$ $\mathrm{PI}^{*} \mathrm{MZ}, 1.9 \% \mathrm{PI}^{*} \mathrm{SZ}$. Despite finding no individuals with PI*ZZ genotype, these high percentages of newly diagnosed AATD carriers suggests the need for continued expansion of screening hospitalized patients with COPD for AATD. Further expansion may lead to the eventual utilization of ancillary hospital staff for testing of individuals.

\section{Conclusion}

The integration of inpatient genetic screening for AATD in COPD patients led to a high rate of newly diagnosed AATD carriers with a variety of AATD genotypes. This novel approach of utilizing resident physicians in the screening process for AATD led to an increased awareness among providers of AATD screening guidelines and treatment options. Furthermore, it is recommended that inpatient screening for AATD in individuals with COPD be expanded regardless of age, severity of symptoms, or smoking history.

\section{Acknowledgments}

We thank David Lester for providing assistance with publication searches. We thank Kathryn Graham, DO, Adrian Brandau, DO, Hussein Al-Mohamad, DO, Donald Foster, DO, Cliff Snellgrove, DO, Michael Kochik, DO and Joshua Turner, DO for aiding with data collection. We thank Arnot Ogden Medical Center's institutional review board for allowing this project to continue. We thank Grifols for providing free testing supplies, materials, and the funding for the blood analyses.

Author contributions: Dr. McLaughlin contributed to the design of the study, data acquisition and analysis and revisions to the article. Dr. Nasir also contributed to the design of the study, data analysis and article revisions. Dr. Tasch is responsible for all aspects of the study and creation, revision and approval of the manuscript for publication.

\section{Declaration of Interest}

The authors have nothing to declare. 


\section{References}

1. Sandhaus RA, Turino G, Brantly ML, et al. The diagnosis and management of alpha-1 antitrypsin deficiency in the adult. Chronic Obstr Pulm Dis. 2016;3(3):668-682.

doi: https://doi.org/10.15326/jcopdf.3.3.2015.0182

2. Sorroche PB, Fernández Acquier M, López Jove O, et al. Alpha-1 antitrypsin deficiency in COPD patients: a cross-sectional study. Arch Bronconeumol. 2015;51(11):539-543.

doi: https://doi.org/10.1016/j.arbres.2015.01.008

3. Silverman EK, Sandhaus RA. Clinical practice. Alpha-1 antitrypsin deficiency. $N$ Engl J Med. 2009;360(26):2749-2757. doi: https://doi.org/10.1056/NEJMcp0900449 .

4. Craig TJ. Suspecting and testing for alpha-1 antitrypsin deficiency: an allergist's and/or immunologist's perspective. $J$ Allergy Clin Immunol Pract. 2015;3(4):506-511. doi: https://doi.org/10.1016/j.jaip.2015.04.005.

5. Greulich T, Vogelmeier CF. Alpha-1-antitrypsin deficiency: increasing awareness and improving diagnosis. Ther Adv Respir Dis. 2016;10(1):72-84.

doi: https://doi.org/10.1177/1753465815602162.

6. American Thoracic Society/European Respiratory Society statement: Standards for the diagnosis and management of individuals with alpha-1 antitrypsin deficiency. Am J Respir Crit Care Med. 2003;168:818-900.

doi: https://doi.org/10.1164/rcem.168.7.818.

7. Aboussouan LS, Stoller JK. Detection of alpha-1 antitrypsin deficiency: a review. Respir Med. 2009;103(3):335-341.

doi: https://doi.org/10.1016/j.rmed.2008.10.006 .

8. Stoller JK, Strange C, Schwarz L, Kallstrom TJ, Chatburn RL. Detection of alpha-1 antitrypsin deficiency by respiratory therapists: experience with an educational program. Respir Care. 2014;59(5):667-672. doi: https://doi.org/10.4187/respcare.02817.

9. Rahaghi FF, Sandhaus RA, Brantly ML, et al. The prevalence of alpha-1 antitrypsin deficiency among patients found to have airflow obstruction. COPD. 2012;9(4):352-358. Erratum in: COPD. 2013;10(4):555.

doi: https://doi.org/10.3109/15412555.2012.669433

10. Global Initiative for Chronic Obstructive Lung Disease (GOLD). Global strategy for the diagnosis, management and prevention of COPD, 2017. GOLD website.http://goldcopd.org/gold-2017globalstrategy-diagnosis-management-prevention-copd/. Published 2017. Accessed December 2017.

11. Chorostowska-Wynimko J. Targeted screening programmes in COPD: how to identify individuals with a1-antitrypsin deficiency. Eur Respir Rev. 2015;24(135):40-45.

doi: https://doi.org/10.1183/09059180.00010614
12. Ferrarotti I, Poplawska-Wisniewska B, Trevisan MT, et al. How can we improve the detection of alpha-1antitrypsin deficiency? PLoS One. 2015;10(8):e0135316. doi: https://doi.org/10.1371/journal.pone.0135316

13. de Serres FJ, Blanco I. Prevalence of a1-antitrypsin deficiency alleles $\mathrm{PI}^{*} \mathrm{~S}$ and $\mathrm{PI}^{*} \mathrm{Z}$ worldwide and effective screening for each of the five phenotypic classes $\mathrm{PI}^{*} \mathrm{MS}, \mathrm{PI}^{*} \mathrm{MZ}, \mathrm{PI}^{*} \mathrm{SS}, \mathrm{PI}{ }^{*} \mathrm{SZ}$, and $\mathrm{PI}^{\star} \mathrm{ZZ}$ : a comprehensive review. Ther Adv Respir Dis. 2012;6(5):277-295.

doi: https://doi.org/10.1177/1753465812457113

14. Stoller JK, Lacbawan FL, Aboussouan LS. Alpha-1 Antitrypsin Deficiency In: Pagon RA, Adam MP, Ardinger $\mathrm{HH}$, et al. GeneReviews. Seattle: University of Washington, Seattle;1993-2018 